\title{
Pharmacophore Modelling of Vanillin Derivatives, Favipiravir, Chloroquine, Hydroxychloroquine, Monolaurin and Tetrodotoxin as MPro inhibitors of Severe Acute Respiratory Syndrome Coronavirus-2 (SARS-CoV-2)
}

\author{
Woon Yi Law*, Mohd Razip Asaruddin*, Showkat Ahmad Bhawani and Samsur Mohamad \\ Programme of Chemistry, Faculty of Resource Science and Technology, Universiti Malaysia Sarawak, 94300 Kota Samarahan, \\ Sarawak, Malaysia
}

*Corresponding authors: Woon Yi Law, Programme of Chemistry, Faculty of Resource Science and Technology, Universiti Malaysia Sarawak, 94300 Kota Samarahan, Sarawak, Malaysia; E-mail: mendah_wylaw@hotmail.com

Mohd Razip Asaruddin, Programme of Chemistry, Faculty of Resource Science and Technology, Universiti Malaysia Sarawak, 94300 Kota Samarahan, Sarawak, Malaysia; E-mail: amrazip@unimas.my

\section{ABSTRACT}

Ligand-based pharmacophore modelling approach using four established antiviral drugs, namely remdesivir, lopinavir, ritonavir and hydroxychloroquine were analysed for COVID-19 inhibitors as training sets. Twenty vanillin derivatives together with monolaurin were used as test sets to evaluate potential as SARS-CoV-2 inhibitors. Structure-based pharmacophore modelling approach was also performed using Protein Data Bank information: PDB-5RE6, 5REX and 5RFZ in order to analyse the binding site and ligand-protein complex interactions. The pharmacophore modelling mode of 5RE6 displayed two Hydrogen Bond Acceptors (HBA) and one Hydrophobic (HY) interaction. Besides, the pharmacophore model of 5REX showed two HBA and two HY interactions. Finally, the pharmacophore model of 5 RFZ showed three HBA and one HY interaction. Based on ligand-based approach, 20 Schiff-based vanillin derivatives, namely vanillin associated with methyl-6aminopyridine-3-carboxylate (1), sepiapterin (2), 6-aminopyridine-3-carboxylic acid (3), 6-aminopyridine-2-carboxylic acid (4), pemoline (5), $\alpha$-phenylglycine (6), 2-amino-4-hydroxy-3-methylpentanoic acid (7), 4-hydroxyphenylglycine (8), $\beta$-homoserine (9), allylglycine (10), oxamic acid (11) benzophenone hydrazine (12), 2-aminoadipic acid (13), D-alanyl-D-alanine (14), p-bromophenylalanine (15), nicotinic hydrazide (16), 4-hydroxybenzhydrazide (17), benzohydrazide (18), isonicotinic hydrazide (19), and phenylhydrazine (20) showed strong MPro inhibition activity. This was due to their good alignment and common features to PDB-5RE6. Similarly, monolaurin and tetrodotoxin displayed some significant activity against SARS-CoV-2. From structure-based approach, vanillin derivatives (1) to (12) displayed some potent MPro inhibition against SARS-CoV-2. Favipiravir, chloroquine and hydroxychloroquine also showed some significant MPro inhibition. Favipiravir showed good alignment and common pharmacophore features to PDB5RFZ, whereas chloroquine and hydroxychloroquine showed good alignment and common pharmacophore features to PDB-5REX.
Keywords

Coronavirus

SARS-CoV

MPro inhibitor pharmacophore modelling vanillin derivatives Favipiravir Chloroquine Hydroxychloroquine Monolaurin Tetrodotoxin 


\section{Mini Review}

Abbreviations: SARS-CoV: Severe acute respiratory syndrome coronavirus; HBA: Hydrogen Bond Acceptors; HY: Hydrophobic; CADD: Computer-aided drug design; WHO: World Health Organization

\section{INTRODUCTION}

In the early $21^{\text {st }}$ century, an outbreak of coronaviruses has been causing a number of diseases. Coronavirus belong to the family of Coronaviridae. Coronaviruses are enveloped, positive-sense, single stranded RNA viruses, with their size approximately 27 to 34 kilobases [1,2]. Out of numerous coronaviruses, seven types of coronaviruses are known for their ability to cause infections and respiratory illnesses in humans [3]. Four types of coronaviruses: 229E, OC43, NL63, and HKU1 are associated with the symptoms of common cold [4]. Another two types of coronaviruses, which are severe acute respiratory syndrome coronavirus (SARS-CoV) and Middle East respiratory syndrome coronavirus (MERS-CoV) were the causal agents of the outbreak of severe acute respiratory syndrome (SARS) in 2002-2003 and Middle East respiratory syndrome in 2012, respectively [4]. Both coronaviruses had accumulated more than 10,000 cases in the past, with $10 \%$ death cases from SARS and $37 \%$ death cases from MERS $[5,6]$.

In December 2019, a novel strain of coronavirus was identified at Wuhan, China, which led to a series of pneumonia cases
[7]. Formerly named as 2019 novel coronavirus (2019-nCoV) by the World Health Organization (WHO), the coronavirus was later named as severe acute respiratory syndrome coronavirus-2 (SARS-CoV-2) due to the genetic resemblance of about $80 \%$ with SARS-CoV $[7,8]$. The disease was named as coronavirus disease 2019 (COVID-19) by WHO [7]. On 30 ${ }^{\text {th }}$ of January 2020, the outbreak of COVID-19 was declared a Public Health Emergency of International Concern (PHEIC), and consequently on $11^{\text {th }}$ of March 2020, an official pandemic was declared $[9,10]$ (Figure 1).

The situation is further aggravated due to the absence of specific medicinal drugs or vaccines that are licensed or approved by the U.S. Food and Drug Administration (FDA) for the treatment of COVID-19 [11].

\section{SARS-CoV-2}

Coronaviruses are divided into four genera, namely $\alpha$-CoVs, $\beta$-CoVs, $\gamma$-CoVs and $\delta$-CoVs [12]. Among these, the $\alpha$-CoVs and $\beta$-CoVs possess ability to infect mammals, whereas the $\gamma$-CoVs and $\delta$-CoVs can infect both birds and mammals [13]. The three coronaviruses, namely, SARS-CoV, MERS-CoV and SARS-CoV-2 belong to $\beta$-CoVs [14]. There are four types of structural proteins found on the surface of coronaviruses: spike $(\mathrm{S})$ protein, envelope $(\mathrm{E})$ protein, membrane $(\mathrm{M})$ protein, and nucleocapsid (N) protein [15] (Figure 2).

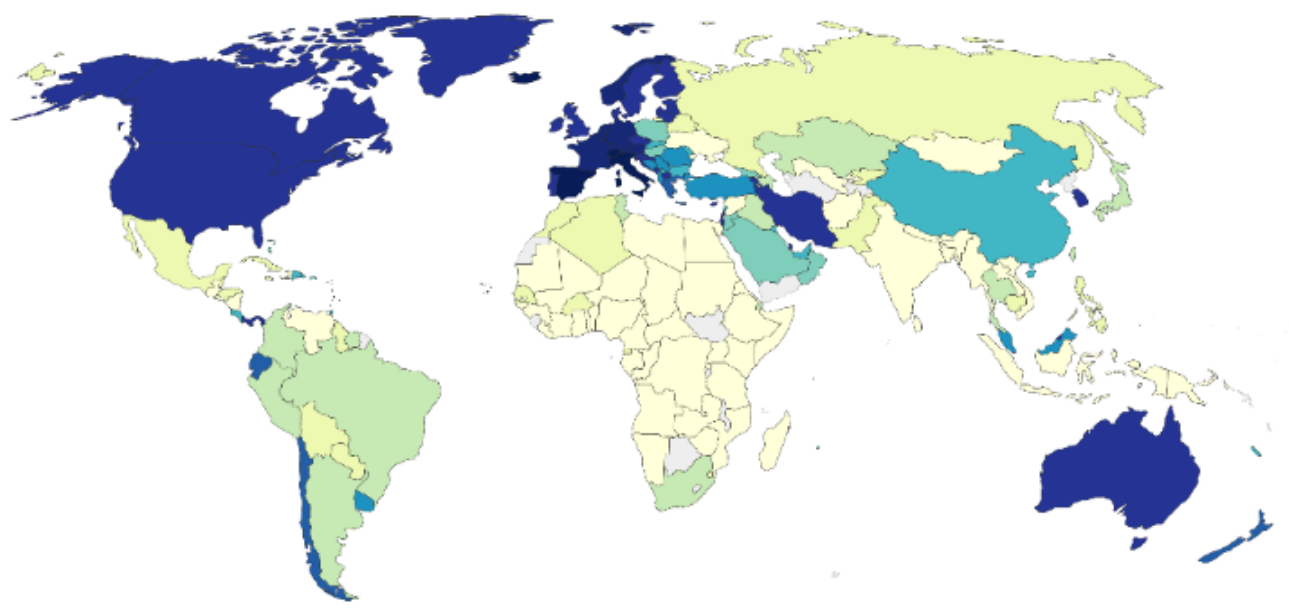

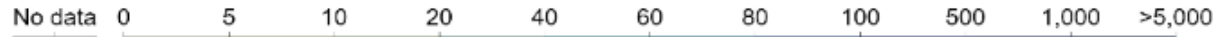



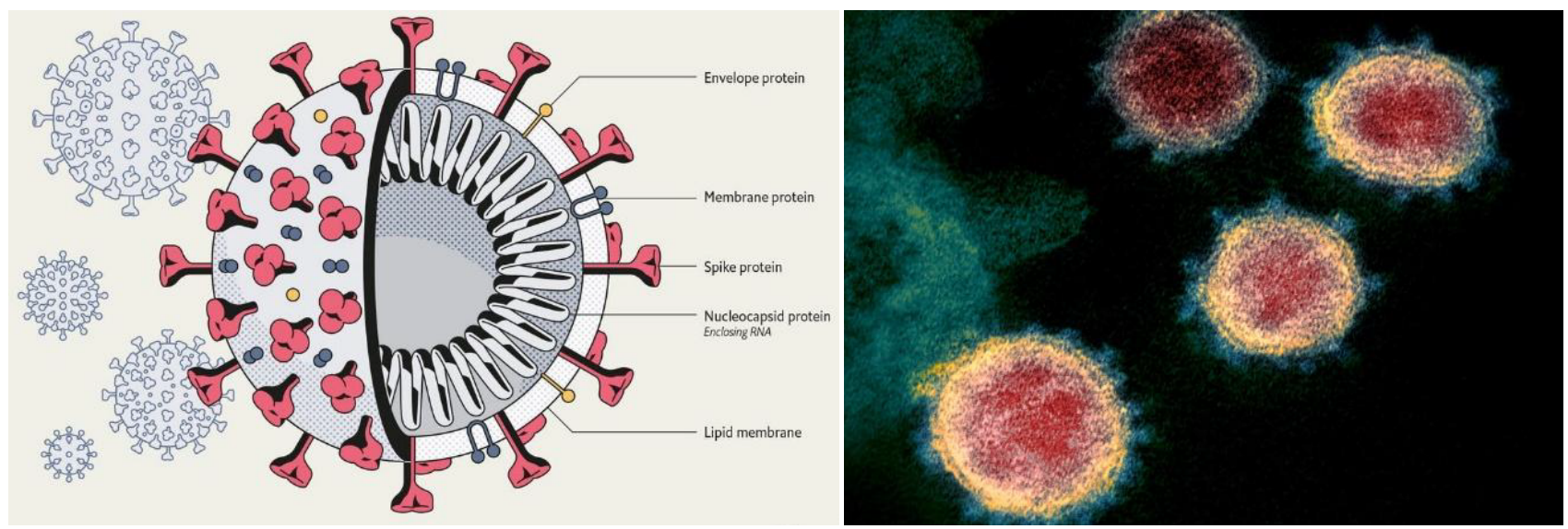

Figure 2.

The attachment and entry of SARS-CoV-2 into the host cell is facilitated by the $\mathrm{S}$ proteins, particularly to the angiotensin converting enzyme 2 (ACE2) receptors of human cells due to great affinity [16]. Therefore, therapies to control the activities of SARS-CoV-2, such as preventing viral RNA synthesis, viral replication or blocking the binding of virus are efforts that researchers are putting on to take care of the issue. In coronaviruses, one of the drug target that is being focused by chemists is the main protease $\left(\mathrm{M}^{\mathrm{Pro}}\right)$ due to its important role in processing viral polyproteins translated from the viral RNA and controlling replicase complex activity $[17,18]$. The activity of $\mathrm{M}^{\text {Pro }}$ should be inhibited to control and prevent the viral action of SARS-CoV-2. In recent times, vanillin derivatives, which are Schiff-based vanillin with primary amines, have been utilised by researchers for different research purposes. From previous reported research, Schiff-based vanillin derivatives have been tested as neuraminidase inhibitors of influenza virus [19]. In addition to this, vanillin and its derivatives had also been tested for their antifungal activity against the human fungal pathogen, Cryptococcus neoformans [20]. Hence in this study, a series of Schiff-based vanillin derivatives will be tested as potent $\mathrm{M}^{\text {Pro }}$ inhibitors of SARS-CoV-2 by means of ligand-based and structure-based pharmacophore modelling in computer-aided drug design (CADD).

\section{$\mathrm{M}^{\text {Pro }}$ inhibitors of SARS-CoV-2}

As the world is combating with the viral disease, the first antiviral drug named Favilavir has been approved by the National Medical Products Administration of China [21]. Despite the fact that Favilavir is yet to be approved by the U.S. Food and Drug Administration (FDA), the ability of the drug to inhibit the action of the RNA-dependent RNA polymerase (RdRp) has been proven [21,22]. The chemical compound, favipiravir, was known as a broad spectrum antiviral drug that showed inhibition against influenza virus [23]. The Ministry of Science and Technology of China reported that patients from Shenzhen which received Favilavir treatment were tested negative for the coronavirus after 4 days being tested positive, as well as $91 \%$ improvement in their lung conditions [22]. From this perspective, in silico screening in CADD will be performed as well to test the potent ability of favipiravir as $\mathrm{M}^{\text {Pro }}$ inhibitors of SARS-CoV-2 (Figure 3).

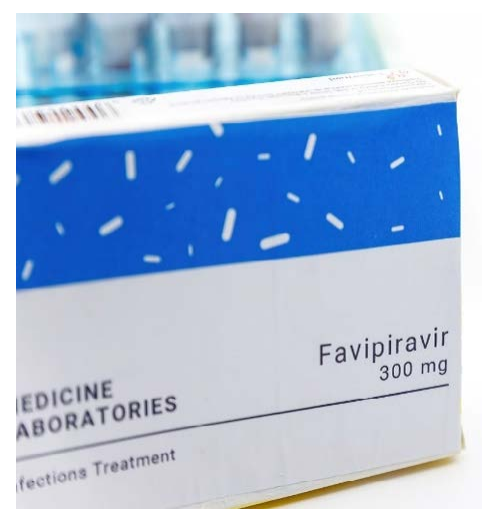

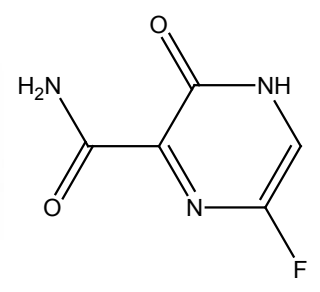

Favipiravir

Figure 3. 


\section{Mini Review}

Chloroquine is a medicinal drug known for its antimalarial activity used to treat malaria, and used as prophylaxis [24,25]. Recently two research teams have reported the in vitro antiviral study of chloroquine against the growth of SARS-CoV-2, which was also further confirmed by providing medication to about 100 COVID-19 patients [26,27]. The study is further affirmed by reporting the antiviral activity of chloroquine in interfering SARS-CoV from binding ACE2 receptors through decreasing the terminal glycosylation of ACE2 receptors, therefore inhibiting virus replication [28]. Simultaneously, one of the recent study found out that the S protein of SARS-CoV-2 is very identical to that of SARS-CoV, which can bind to the ACE2 receptors [16]. A derivative of chloroquine, namely, hydroxychloroquine, was reported to be more soluble and less toxic than chloroquine [25]. Similarly, by interfering the glycosylation of ACE2 receptor, hydroxychloroquine is also a potential COVID-19 pharmacological agent for its in vitro antiviral activity being tested against SARS-CoV-2 [29]. The Chinese Clinical Trial Registry performed seven clinical trial registries on hydroxychloroquine to determine its efficacy in treating COVID-19 [29]. Despite all the research and reported trials, none of them are conclusive enough to confirm the effectivity of chloroquine and hydroxychloroquine as antiSARS-CoV-2 drug. A placebo-controlled trial reported on using hydroxychloroquine as postexposure prophylaxis showed that there was no significant difference between patients receiving hydroxychloroquine treatment and patients receiving placebo [30]. The research concluded that hydroxychloroquine did not successfully prevent COVID-19 after high-risk or moderaterisk exposure. Also, chloroquine was reported to be used together with other antiviral drugs in treatment of COVID-19, alone itself is inefficient against SARS-CoV-2. 14 Italian tourists that were reported positive for COVID-19 in Medanta Hospital were recovered by treatment using lopinavir, azithromycin and chloroquine, but reported that chloroquine did not contribute much [31]. More research on chloroquine and hydroxychloroquine as antiviral drugs for SARS-CoV-2 is necessary (Figure 4).

Coconut oil and its derivatives have been long reported for their antiviral and antibacterial activity, particularly lauric acid and monolaurin were utilised as feed supplements in farm animals [32]. It was also reported that lauric acid and its derivative, monolaurin, exhibit potential in vitro antiviral activity against SARS-CoV-2 [33]. This was reported by Dr. Fabian Dayrit and Dr. Mary Newport from Philippines elaborating the potential of coconut oil as antiviral agent against COVID-19 based on three mechanisms, disintegration of the virus membrane, inhibition of virus maturation and prevention of binding of viral proteins to the host cell membrane [33]. For their potent antiviral activity, monolaurin is selected for in silico screening in CADD. Tetrodotoxin, a potent neurotoxin, is mostly found in pufferfish [34]. Tetrodotoxin was known as sodium channel blocker, preventing messages to be delivered by the nervous system [35]. Despite the fact being 1200 times more toxic than cyanide, the analgesic activity of tetrodoxin was applied by researchers in discovery of drugs for pain relief, for example in severe cancer [36]. As suggested by faculty member from the aquatic resource science and management programme for its use as pain relief drugs, tetrodotoxin is selected for in silico screening in CADD for its antiviral activity test in SARS-CoV-2 (Figure 5).

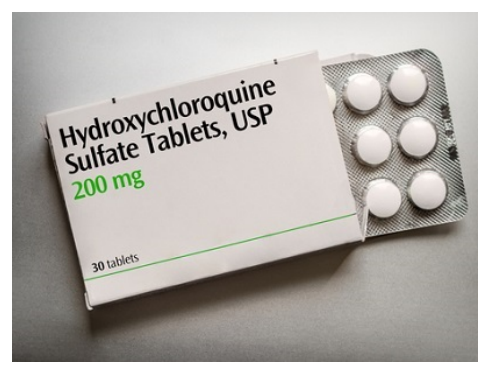

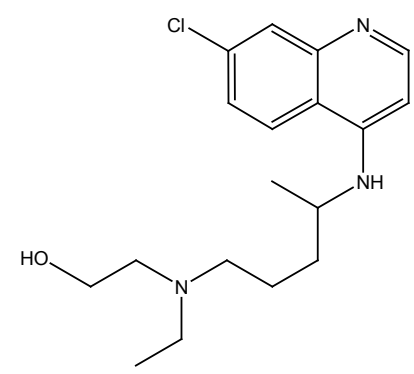

Hydroxychloroquine

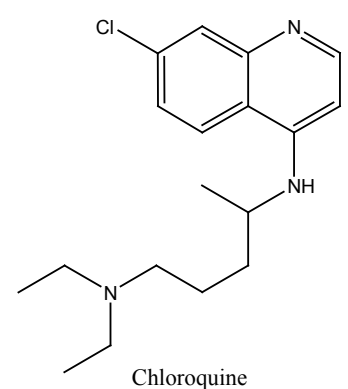

Figure 4. 

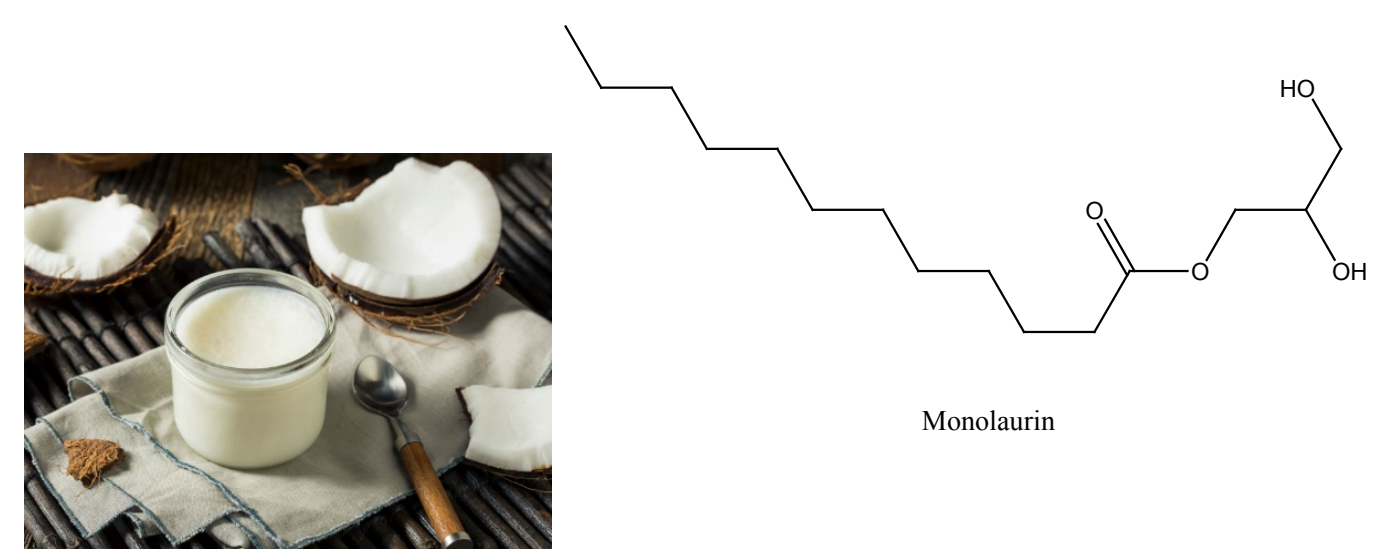

Monolaurin

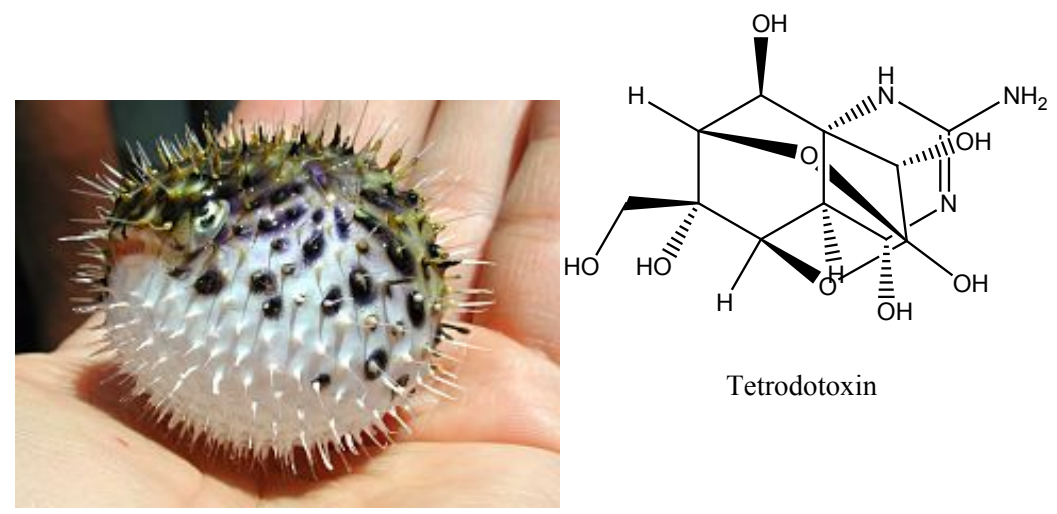

Figure 5.

\section{CONCLUSION}

From the ligand-based pharmacophore modelling approach, it was concluded that the 20 vanillin derivatives, compound (1) to (20), exhibited significant antiviral activity regarded as $\mathrm{M}^{\mathrm{Pro}}$ inhibitors of SARS-CoV-2. Thus, it means that these potential compounds have some capability to fight COVID-19. Furthermore, monolaurin and tetrodotoxin are also a potent active compounds against SARS-CoV-2 according to ligand-based approach. Further result from structure-based pharmacophore modelling approach suggested that vanillin derivatives (1) to (12) displayed good result as potent COVID-19 antiviral active compounds. Those established marketed drugs such as favipiravir, chloroquine and hydroxychloroquine have proven to possess potent antiviral activity as $\mathrm{M}^{\text {Pro }}$ inhibitors of SARS-CoV-2 against COVID-19 in silico. Further investigation should be done in order to ensure the safety and lethality of these compounds.

\section{REFERENCES}

1. Huang C, Wang Y, Li X, Ren L, Zhao J, Hu Y, ... Cao B: Clinical features of patients infected with 2019 novel coronavirus in Wuhan, China. Lancet. 2020, 395: 497-506. 10.1016/S0140-6736(20)30183-5
2. Sexton NR, Smith EC, Blanc H, Vignuzzi M, Peersen OB, Denison MR: Homology-Based Identification of a Mutation in the Coronavirus RNA-Dependent RNA Polymerase That Confers Resistance to Multiple Mutagens. J Virol. 2016, 90: 7415-7428. 10.1128/jvi.00080-16

3. Tesini BL: Coronaviruses and Acute Respiratory Syndromes (COVID-19, MERS, and SARS). MSD Manuals. 2020. https://www.msdmanuals.com/professional/infectiousdiseases/respiratory-viruses/coronaviruses-and-acuterespiratory-syndromes-covid-19,-mers,-and-sars

4. Zhu N, Zhang D, Wang W, Li X, Yang B, Song J, ... Tan W: A novel coronavirus from patients with pneumonia in China, 2019. New Engl J Med. 2020, 382: 727-733. 10.1056/NEJMoa2001017

5. World Health Organization: Summary of probable SARS cases with onset of illness from 1 November 2002 to 31 July 2003. 2003. https://www.who.int/csr/sars/country/ table2004_04_21/en/

6. World Health Organization: Middle East respiratory syndrome coronavirus (MERS-CoV). 2019. https://www. who.int/emergencies/mers-cov/en/ 
7. Guo YR, Cao QD, Hong ZS, Tan YY, Chen SD, Jin HJ, ... Yan Y: The origin, transmission and clinical therapies on coronavirus disease 2019 (COVID-19) outbreak - an update on the status. Mil Med Res. 2020, 7. 10.1186/ s40779-020-00240-0

8. Zhang L, Lin D, Sun X, Curth U, Drosten C, Sauerhering L, ... Hilgenfeld R: Crystal structure of SARS-CoV-2 main protease provides a basis for design of improved $\alpha$-ketoamide inhibitors. Science. 2020. 10.1126/science. abb3405

9. World Health Organization: Statement on the second meeting of the International Health Regulations (2005) Emergency Committee regarding the outbreak of novel coronavirus (2019-nCoV). 2020. https://www.who.int/ news-room/detail/30-01-2020-statement-on-the-secondmeeting-of-the-international-health-regulations-(2005)emergency-committee-regarding-the-outbreak-of-novelcoronavirus-(2019-ncov)

10. World Health Organization: WHO Director-General's opening remarks at the media briefing on COVID-19. 2020. https://www.who.int/dg/speeches/detail/whodirector-general-s-opening-remarks-at-the-media-briefingon-covid-19---11-march-2020

11. Bergman SJ, Cennimo DJ, Miller MM, Olsen KM: Treatment of Coronavirus Disease 2019 (COVID-19): Investigational Drugs and Other Therapies. Medscape. 2020. https:// emedicine.medscape.com/article/2500116-overview

12. Yin Y, Wunderink RG: MERS, SARS and other coronaviruses as causes of pneumonia. Respirology. 2017 23: 130-137. 10.1111/resp.13196

13. Chen Y, Liu Q, Guo D: Emerging coronaviruses: Genome structure, replication, and pathogenesis. J Med Virol. 2020, 92: 418-423. 10.1002/jmv.25681

14. Walls AC, Park Y, Tortorici MA, Wall A, McGuire AT, Veesler D: Structure, Function, and Antigenicity of the SARS-CoV-2 Spike Glycoprotein. Cell. 2020, 180: 281292. 10.1016/j.cell.2020.02.058

15. Schoeman D, Fielding BC: Coronavirus envelope protein: current knowledge. Virol J. 2019, 16. 10.1186/s12985-0191182-0

16. Xu X, Chen P, Wang J, Feng J, Zhou H, Li X, ... Hao P: Evolution of the novel coronavirus from the ongoing Wuhan outbreak and modeling of its spike protein for risk of human transmission. Science China Life Sciences. 2020, 63: 457-460. 10.1007/s11427-020-1637-5

17. Cheng VC, Lau SK, Woo PC, Kwok YY: Severe acute respiratory syndrome coronavirus as an agent of emerging and reemerging infection. Clin Microbiol Rev. 2007, 20: 660-694. 10.1128/CMR.00023-07
18. Xue X, Yu H, Yang H, Xue F, Wu Z, Shen W, ... Rao Z: Structures of Two Coronavirus Main Proteases: Implications for Substrate Binding and Antiviral Drug Design. J Virol. 2008, 82: 2515-2527. 10.1128/jvi.02114-07

19. Asaruddin MR: Modelling And Syntheses Of Vanillin Derivatives Targeting Influenza Virus Neuraminidase. Malaysian Academic Library Institutional Repository. 2016. http://eprints.usm.my/45418/1/MOHD\%20 RAZIP\%20ASARUDDIN.pdf

20. Kim JH, Lee HO, Cho YJ, Kim J, Chun J, Choi J, ... Jung $\mathrm{WH}$ : A vanillin derivative causes mitochondrial dysfunction and triggers oxidative stress in Cryptococcus neoformans. PLoS ONE. 2014, 9. 10.1371/journal.pone.0089122

21. The Science Times: 'Favilavir': First Approved Drug to Possibly Treat Coronavirus. 2020. https://www. sciencetimes.com/articles/25053/20200317/favilavir-firstapprove-drug-treat-coronavirus.htm

22. Hospimedica: Fujifilm's Antiviral Becomes First Approved Drug to Treat Coronavirus in China. 2020. https://www. hospimedica.com/coronavirus/articles/294781247/ fujifilms-antiviral-becomes-first-approved-drug-to-treatcoronavirus-in-china.html

23. Goldhill DH, Te Velthuis AJW, Fletcher RA, Langat P, Zambon M, Lackenby A, Barclay WS: The mechanism of resistance to favipiravir in influenza. Proc Natl Acad Sci USA. 2018, 115: 11613-11618. 10.1073/pnas.1811345115

24. Romanelli F, Smith K, Hoven A: Chloroquine and Hydroxychloroquine as Inhibitors of Human Immunodeficiency Virus (HIV-1) Activity. Curr Pharm Design. 2004, 10: 2643-2648. 10.2174/1381612043383791

25. The Centre for Evidence-Based Medicine: Chloroquine and hydroxychloroquine: Current evidence for their effectiveness in treating COVID-19. 2020. https://www. cebm.net/covid-19/chloroquine-and-hydroxychloroquinecurrent-evidence-for-their-effectiveness-in-treatingcovid-19/

26. Wang M, Cao R, Zhang L, Yang X, Liu J, Xu M, ... Xiao G: Remdesivir and chloroquine effectively inhibit the recently emerged novel coronavirus (2019-nCoV) in vitro. Cell Res. 2020, 30: 269-271. 10.1038/s41422-020-0282-0

27. Xia J, Liu X, Chen H, Shang Y, Zhu H, Chen G, ... Hong $\mathrm{Z}$ : Efficacy of Chloroquine and Lopinavir/Ritonavir in mild/general COVID-2019: a prospective, open-label, multicenter randomized controlled clinical study. 2020. 10.21203/rs.3.rs-16392/v1

28. Vincent MJ, Bergeron E, Benjannet S, Erickson BR, Rollin PE, Ksiazek TG, ... Nichol ST: Chloroquine is a potent inhibitor of SARS coronavirus infection and spread. Virol J. 2005, 2: 69. 10.1186/1743-422X-2-69 
29. Liu J, Cao R, Xu M, Wang X, Zhang H, Hu H, ... Wang M: Hydroxychloroquine, a less toxic derivative of chloroquine, is effective in inhibiting SARS-CoV-2 infection in vitro. Cell Discov. 2020, 6. 10.1038/s41421-020-0156-0

30. Boulware DR, Pullen MF, Bangdiwala AS, Pastick KA, Lofgren SM, Okafor EC: A Randomized Trial of Hydroxychloroquine as Postexposure Prophylaxis for Covid-19. N Engl J Med. 2020, 383: 517-525. 10.1056/ NEJMoa2016638

31. Chandra H: Paracetamol, chloroquine \& Google translator: How Medanta treated Italians with coronavirus. The Print. 2020. https://theprint.in/health/paracetamol-chloroquinegoogle-translator-how-medanta-treated-italians-withcoronavirus/387144/

32. Baltić B, Starčević M, Dordević J, Mrdović B, Marković $\mathrm{R}$ : Importance of medium chain fatty acids in animal nutrition. IOP Conf Ser Earth Environ Sci. 2017, 85: 12048. $10.1088 / 1755-1315 / 85 / 1 / 012048$
33. Dayrit FM, Newport MT: The Potential of Coconut Oil and its Derivatives as Effective and Safe Antiviral Agents Against the Novel Coronavirus (nCoV-2019). Integrated Chemists of Philippines. 2020. https://www. icp.org.ph/2020/01/the-potential-of-coconut-oil-and-itsderivatives-as-effective-and-safe-antiviral-agents-againstthe-novel-coronavirus-ncov-2019/

34. Hwang DF, Noguchi T: Tetrodotoxin Poisoning. Adv Food Nutr Res. 2007, 52: 141-236. 10.1016/S10434526(06)52004-2

35. Bane V, Lehane M, Dikshit M, O’Riordan A, Furey A: Tetrodotoxin: Chemistry, toxicity, source, distribution and detection. Toxins. 2014, 6: 693-755. 10.3390/toxins6020693

36. Neil AH, Patrick DS, Bernard L, May OL, Benoit D, David W, Robin L, Anh HN: Tetrodotoxin for Moderate to Severe Cancer Pain: A Randomized, Double Blind, Parallel Design Multicenter Study. 35: 420-429. 10.1016/j. jpainsymman.2007.05.011

Citation: Law WY, Asaruddin MR, Bhawani SA, Mohamad S (2021) Pharmacophore Modelling of Vanillin Derivatives, Favipiravir, Chloroquine, Hydroxychloroquine, Monolaurin and Tetrodotoxin as MPro inhibitors of Severe Acute Respiratory Syndrome Coronavirus-2 (SARS-CoV-2). Appl Cell Biol, 9(1), 2021 [8-14] 